and the goat and the haemochorial placentae of the rabbit and the guinea pig. Placenta 1981;suppl 2: 203-14.

3 Canning J, Boyd RDH. Mineral and water exchanged between mother and fetus. In: Beard RW, Nathanielsz PW eds. Fetal physiology and medicine. New York: Marcel Dekker, 1984:481-509.

4 Fantel AG. Fetomaternal potassium relations in the fetal rat on the twentieth day of gestation. Pediatr Res 1975;9: 527-30.
5 Moniz CF, Nicolaides KH, Bamforth FJ, Rodeck $\mathrm{CH}$. Normal reference ranges for biochemical substances relating to renal, hepatic, and bone function in fetal and maternal to renal, hepatic, and bone function in etal and maternal plasma the

6 Dancis J, Springer D. Fetal homeostasis in maternal malnutrition: potassium and sodium deficiency in rats. Pediatr Res 1974;4:345-51.

\title{
Anatomy and development of the fontanelle
}

M Sundaresan, $M$ Wright, A B Price

\begin{abstract}
Anterior fontanelles from 19 fetuses over a range of gestational ages (from 8 weeks to full term) were obtained to study the anatomy and development in relation to the application of the principles of fontanometry. The most important feature was the development of an elastic membrane by 23 weeks' gestation; a subcutaneous layer of fat had appeared by 28 weeks' gestation.
\end{abstract}

The applanation principle can be applied to a method of measuring intracranial pressure, and the anterior fontanelle is the usual site. Inaccuracies in measurement may arise from variations in the elasticity of the fontanelle at different stages of gestation, or from there being too small a surface on which to fix the sensor, which is at least $1 \mathrm{~cm}$ in diameter. This study was undertaken to try and detect structural changes that might explain inaccuracies in fontanometry. Many methods have been used to measure fontanelle size and we used a modification of Scammon's technique.

\section{Material and methods}

Nineteen fontanelles were examined over a developmental period ranging from a fetus of 8 weeks' gestation to a full term neonate who died four weeks after birth

The surface area of the non-macerated fontanelle was measured by placing soft paper over the previously dried skin, palpating the corners of the fontanelles and rubbing over these corners and edges with a soft pencil. This produced a crude 'brass rubbing' of the outline of the fontanelle. This was transferred to graph paper by pricking through it with a pin. The squares within the outline were counted, and the area in square centimetres recorded. ${ }^{2}$ In addition, the shortest diameter of each fontanelle (Elasser's diameter) was measured, as during fontanometry it is important that the sensor does not touch the edges of the fontanelle.

Blocks for microscopy were taken by excising the fontanelle together with a $0.5 \mathrm{~cm}$ rim of bone. A slice was trimmed across the middle of the block to include bone at either side. In the case of a necropsy fetus a coronal skin incision was made, and this incision formed the anterior edge of the block that was taken coronally across the posterior half of the fontanelle. The skin was sutured to the rest of the block before processing. Blocks were decalcified with $10 \%$ formic acid, routinely processed and embedded in paraffin; 3 to 5 micron sections were stained with haematoxylin and eosin, and elastic van Gieson's stain.

\section{Results}

The gestational ages of the fontanelles are shown in table 1 .

\section{ANATOMY}

The fontanelle was defined laterally by the bony skull plates and so could not be delineated until 12 weeks' gestation when these first appeared.

From the lateral to the medial edges, the bony plates gave way to islands of bone and then to aggregates of plump fibroblasts surrounding pink osteoid like material. At the centre of the fontanelle no precursors of bone were present. The vertical structure of the fontanelle was best considered in levels: level 1 comprised the skin; level 2 comprised the connective tissue below level 1 and the bony skull plates; level 3 was the connective tissue between level 2 and the dura; and level 4 was the dura (fig la).

At 8 weeks' gestation level 1 (the skin) was a single layer of flat epithelial cells. This became stratified epithelium by 16 weeks, with a dermis containing hair follicles. By 19 weeks occasional sebaceous glands could be seen. By 23 weeks small clusters of fat cells had developed in the dermis. By 28 weeks a continuous layer of subcutaneous fat had developed; no major structural alteration occurred after this time. In levels 2 and 3 there were slight increases in the density of the collagen as gestation increased. Level 4 (dura) consisted of a single layer of cells until 28 weeks' gestation, when two layers of cells became visible. The distribution of elastin changed with increasing gestation; it was first seen as diffuse strands within dural vessels at $\mathbf{1 6}$ weeks, but a well defined elastic lamina had formed by 19 weeks' gestation. At this time wisps of elastin were seen in the connective tissue between levels 1 and 2 . By 23 weeks a well defined elastic membrane had developed at this point (fig lb). This membrane was present

Table 1 Gestational ages of the 19 fontanelles studied

\begin{tabular}{ll}
\hline $\begin{array}{l}\text { Gestational } \\
\text { age (weeks) }\end{array}$ & $\begin{array}{l}\text { No of } \\
\text { fontanelles }\end{array}$ \\
\hline 8 & 1 \\
$12-16$ & 5 \\
$19-22$ & 4 \\
$23-27$ & 4 \\
$28-52$ & 5 \\
\hline
\end{tabular}

Du Cane Road,

Accepted 28 November 1989 

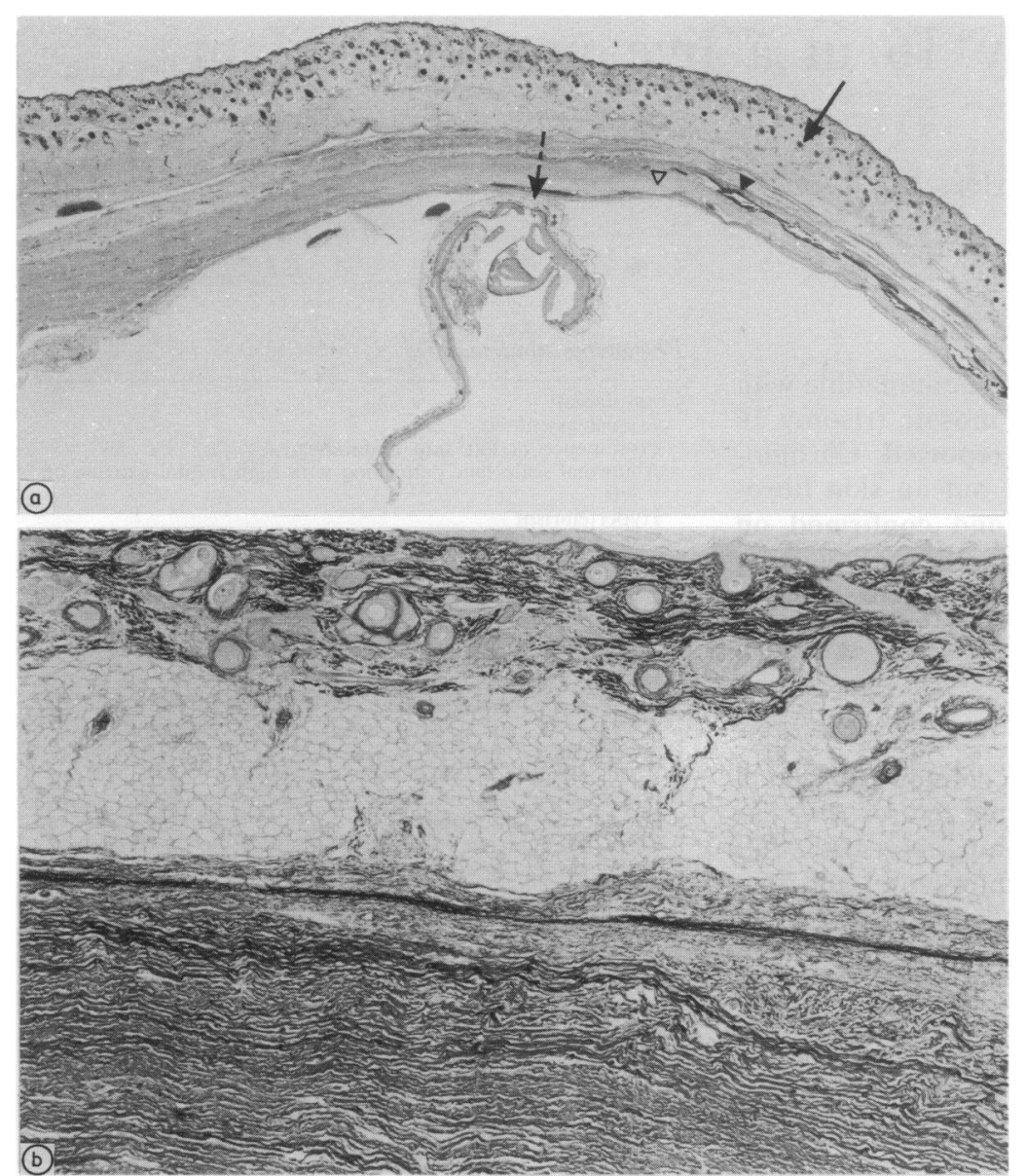

Figure Ia Section of the fontanelle showing four levels: (i) skin (solid arrow); (ii) connective tissue containing skull plates (solid triangle) and islands of bone; (iii) connective tissue beneath second layer (open triangle); and (iv) dura (dotted arrow), with adherent superficial cerebral cortex (Haematoxylin and eosin, magnification $\times 8 \cdot 5)$. Figure $1 b$ Section of 28 week old fontanelle showing elastin membrane and fat layer (elastic van Gieson's stain, magnification $\times 65$ ).
Table 2 Changes in mean surface area and Elasser's diameter with gestational age

\begin{tabular}{lll}
\hline $\begin{array}{l}\text { Gestational } \\
\text { age (weeks) }\end{array}$ & $\begin{array}{l}\text { Surface area } \\
\left(\mathrm{mm}^{2}\right)\end{array}$ & $\begin{array}{l}\text { Elasser's } \\
\text { diameter }(\mathrm{cm})\end{array}$ \\
\hline 14 & $5 \cdot 50$ & 1.65 \\
15 & 3.06 & 1.65 \\
16 & 5.31 & $2 \cdot 15$ \\
17 & 5.19 & $2 \cdot 25$ \\
19 & 1.37 & 1.25 \\
21 & 1.56 & 1.30 \\
23 & 3.06 & 1.80 \\
31 & 1.25 & Not measured \\
52 & 1.50 & 1.25 \\
\hline
\end{tabular}

SURFACE AREAS

As gestation increased surface area decreased exponentially. Elasser's diameter hardly changed at all with respect to the size of the $1 \mathrm{~cm}$ sensor (fig 2, table 2).

\section{Discussion}

Important changes in the structure of the fontanelle were noted-in particular, the formation of a well defined elastic membrane by 23 weeks, although the density of this varied among specimens. Fat became apparent as early as 23 weeks, and had formed a thick subcutaneous layer by 28 weeks. If fontanometry is carried out on babies born at full term, these structures would be fully developed and under normal conditions little variation would be expected. More variation in density of the elastic membrane was seen in fontanelles between 23 and 28 weeks, and so we postulate that changes in the density of these structures may cause inaccuracies in fontanometry in younger fetuses. The second factor in assessing accuracy of measurements is size of the fontanelle, and it can be seen from the results that in the age group in which fontanometry was applied the size was relatively constant at different gestational ages. The fontanometry sensor should fit on to the fontanelle of a baby as young as 3 weeks of age.

The eventual closure of the fontanelle presumably occurs by transformation of fibroblasts into osteoblasts. These form bony islands that join to the main skull plate. A study of a larger number of fontanelles at each gestational age would provide more data about individual variations in anatomy, but this study has shown that an elastin membrane does develop between the skin and the plane of the bony plates. We believe that this might be important in assessing the results of fontanometry in younger preterm fetuses.

1 Mehta A, Wright BM, Short C. Clinical fontanometry in the newborn. Lancet 1988;i:754-6.

Scammon RE. The geometric relationships of the anterior fontanelle in infancy. Anat Rec 1930;46:349-63. 